\title{
As construções com o verbo começar no Português do Brasil e a noção de inceptividade aspectual
}

\author{
Giovanna Cristina Rodrigues Alves Rafael* \\ Sueli Maria Coelho**
}

\begin{abstract}
Resumo
Neste estudo, pretendemos identificar as diferentes construções em que o verbo começar aparece no português brasileiro (PB), no intuito de verificar como o aspecto inceptivo se manifesta em cada uma dessas construções, uma vez que o referido verbo é o mais frequente na atualização da categoria aspectual em análise. (TRAVAGLIA, 1986; BARROSO, 1994). Baseandonos em postulados da Gramática de Construções, mais especificamente no Princípio da Não-Sinonímia de Goldberg (1995), lançamos a hipótese de que a inceptividade aspectual não se manifesta da mesma maneira nos tipos diferentes de construções com começar. Os dados utilizados nas análises foram extraídos, majoritariamente, de textos orais e escritos no PB, compreendidos entre os séculos XIX e XXI. Os resultados evidenciaram, à primeira vista, seis tipos de construções, dentre elas as construções perifrásticas e as intransitivas de perspectiva ergativa. Com relação à marcação do aspecto inceptivo, deparamo-nos com algumas limitações de análise, mas verificamos algumas possíveis contradições ao Princípio da Não-Sinonímia de Goldberg (1995).
\end{abstract}

Palavras-chave: aspecto inceptivo. Verbo COMEÇAR. Gramática de Construções. Princípio da Não-Sinonímia. Português Brasileiro.

\section{Considerações iniciais}

O chamado aspecto inceptivo, indicador da fase inicial de um fato/situação verbal, é conhecido por ser o tipo aspectual mais recursivo, dentre os tipos presentes do português, pois dispõe de diversas construções para ser marcado. ${ }^{1}$

1 Os termos inceptivo e incoativo costumam ser empregados como variantes na literatura sobre o aspecto em português. (TRAVAGLIA, 1986; COSTA, 1990).

* Universidade Federal de Minas Gerais - UFMG. Mestra em Estudos Linguísticos (UFMG). Professora da rede pública de ensino básico de Minas Gerais.

** Universidade Federal de Minas Gerais - UFMG Doutora em Estudos Linguísticos (UFMG). Professora da Faculdade de Letras da UFMG. 
(BARROSO, 1994). Entram nesse rol, por exemplo, perífrases como $<\mathrm{V} 1_{\text {pôr-se }}+$ (a) $+\mathrm{V} 2>,<\mathrm{V} 1_{\text {danar }}+$ (a) $+\mathrm{V} 2>$ e $<\mathrm{V} 1_{\text {dar }}+\mathrm{p}(\mathrm{a}) \mathrm{ra}+\mathrm{V} 2>$, além das construções com o verbo começar, o mais prototípico da categoria. (TRAVAGLIA, 1986; BARROSO, 1994).

Analisando o verbo começar, especificamente, percebe-se que, além das construções perifrásticas - as quais, por si só, são bastante amplas, tendo em vista o preenchimento do V2 -, ele pode integrar construções argumentais em que ele aparece como verbo único, como, por exemplo, as construções intransitivas inacusativas de perspectiva ergativa: ${ }^{2}$

\section{( 1 ) “Começou a ouvertura...”. (MACEDO, 1844).}

Uma vez que tal verbo pode figurar em diferentes construções, surgiu-nos o questionamento se a noção de inceptividade, como categoria aspectual, manifestase da mesma maneira em cada uma das construções. Partindo, portanto, desse questionamento e da carência de estudos mais detalhados sobre o assunto, pretendemos descrever, neste artigo, as diferentes construções das quais o verbo começar pode participar, bem como analisar a marcação do aspecto inceptivo em cada uma delas. ${ }^{3}$ Acreditamos que esse tipo aspectual não se manifesta igualmente, ou não se manifesta em algumas das construções, hipótese que se embasa no Princípio da Não-Sinonímia de Goldberg (1995) e que nos propusemos a testar empiricamente.

Para descrevermos e para categorizarmos as construções com começar, adotamos a descrição de construções do português propostas por Perini (2008) chamadas, pelo autor, de diáteses. ${ }^{4}$ Nosso corpus, que conta com 178 construções, compõe-se de textos de fala e de escrita do português brasileiro (PB), produzidos no período que vai desde o início do século XIX ao século XXI. ${ }^{5}$ Os dados de língua

2 Os verbos inacusativos são aqueles que não possuem sujeito em estrutura profunda e que selecionam um argumento afetado (paciente). (CIRÍACO, 2007). A perspectiva ergativa, que pode ser veiculada por construções inacusativas, é aquela em que o argumento alçado para a posição de sujeito tem papel temático de afetado (paciente), implicando, pois, uma mudança de estado do sujeito. (CIRÍACO, 2007). 3 Durante o período em que esta pesquisa foi realizada, fizemos uma pesquisa paralela, no intuito de encontrar trabalhos sobre o aspecto inceptivo e sobre o verbo começar, especificamente. No entanto, não encontramos trabalhos que contemplassem o verbo começar de maneira detalhada, apenas algumas menções rápidas a esse verbo. Sobre o aspecto inceptivo, há os trabalhos de Sigiliano (2012, 2013), os quais tratam do tema numa perspectiva cognitivista.

4 Segundo Perini (2008, p. 237), pode-se definir diátese como "uma construção definida em termos simbólicos, considerada como entorno possível de ocorrência de um verbo". O conjunto de diáteses de um verbo forma sua valência. (PERINI, 2008).

5 De acordo com alguns pesquisadores, como Tarallo (1996 [1993]), o português brasileiro se consolidou como variedade da língua portuguesa após os anos 1800. Por esse motivo, coletamos os dados após a data estipulada. 
oral compreendem tanto peças de teatro quanto corpora transcritos diretamente da fala (760 páginas de textos, no total), e os dados de língua escrita pertencem ao gênero romance (primeiras cem páginas do texto ficcional de cada uma das obras selecionadas - 500 páginas de textos, no total). ${ }^{6}$ Quando não encontramos exemplos das construções listadas por Perini (op. cit.) no corpus, lançamos mão do nosso conhecimento de falantes para levantarmos exemplos que nos permitissem analisá-las, o denominado dado de introspecção.

Os pressupostos teóricos que nortearam esta pesquisa pertencem à vertente cognitiva da Linguística conhecida como Gramática de Construções, mais especificamente aos trabalhos de Goldberg $(1995,2006)$. Além disso, este estudo se dedica à categoria linguística de aspecto. Nas seções a seguir, apresentamos, respectivamente, tais pressupostos teóricos e os resultados que conseguimos alcançar, até o momento, já que o que aqui se apresenta integra um projeto maior de descrição do aspecto inceptivo na Língua Portuguesa.

\section{A categoria aspectual}

A literatura sobre a categoria aspectual congrega algumas divergências, como, por exemplo, a própria terminologia da área. (ALMEIDA, 1980; COSTA, 1990). Mesmo assim, algumas convergências, surgidas das pesquisas dedicadas a esse campo, podem ser identificadas. Pode ser citada, por exemplo, a própria definição de aspecto, que consiste na duração do processo temporal interno de uma estrutura verbal. (COMRIE, 1976; TRAVAGLIA, 1986; COSTA, 1990).

Pode-se afirmar que o aspecto é, pois, uma categoria temporal. Entretanto, por se referir à temporalidade interna da situação, ele não depende do momento da enunciação para se manifestar na língua, como dependem as noções de passado, de presente e de futuro, o que faz dele uma categoria não dêitica. (COMRIE, 1976).

Na língua portuguesa, segundo Travaglia (1986), o aspecto pode indicar a duração de uma situação (limitada, ilimitada, contínua e descontínua) e as fases dessa situação, como seu desenvolvimento (início, meio e fim), seu completamento (situação completa e situação incompleta) e sua realização (por começar, começada

6 Apesar da discrepância entre os números de páginas dos textos de oralidade e de escrita, os dados coletados foram mais recorrentes na modalidade escrita. Rafael (2016), que utiliza o mesmo corpus em sua pesquisa, cita hipóteses que tentam explicar por que essa configuração de dados ocorreu. 
ou não acabada, acabada). O aspecto inceptivo, tipo aspectual ao qual o objeto deste estudo se relaciona, pertence ao chamado aspecto de fases, pois ele indica a fase inicial de uma situação. (BARROSO, 1994).

Dentre os recursos de marcação aspectual disponíveis na língua portuguesa perífrases verbais, advérbios, adjetivos, substantivos e o próprio verbo (cf. COSTA, 1990) - a perífrase verbal é a que mais se destaca. ${ }^{7}$ (COSTA, 1990; BARROSO, 1994). Segundo Barroso (1994), de todas as construções aspectuais, as perífrases inceptivas são as mais recorrentes, isso porque o aspecto inceptivo perifrástico é o que mais dispõe de combinações entre $\mathrm{V} 1_{\text {auxiliar }}$ e $V 2_{\text {principal }}$ para a expressão da categoria aspectual. Além dessas, podem ser identificadas outras construções que, de acordo com alguns pesquisadores, como Travaglia (1986), também marcam o aspecto inceptivo, tais como aquelas formadas com os verbos principiar, começar e iniciar(-se) sem integrarem construções perifrásticas. Segundo demonstram nossos dados, o verbo começar não apresenta um padrão construcional único, o que nos leva a acreditar, com base no Princípio da Não-Sinonímia da Gramática de Construções (GOLDBERG, 1995), que essas diferenças sintáticas acarretam também diferenças semântico-pragmáticas que podem influenciar na marcação da categoria aspectual.

\section{A Gramática de Construções}

A Gramática de Construções, que tem suas origens na Linguística Cognitiva, surgiu com os trabalhos de Fillmore, O’Connor e Kay (1988), sendo, posteriormente, desenvolvida, entre outros estudiosos, por Goldberg (1995) e por Croft (2007). Para os teóricos construcionistas, as construções linguísticas são estruturas que pareiam forma e significado, por meio de uma ligação simbólica. (FERRARI, 2010). Goldberg $(1995,2006)$ é uma das autoras mais citadas, no que diz respeito a essa definição de construção. Segundo ela,

C é uma construção se $\mathrm{C}$ é um par forma-significado $<\mathrm{Fi} \mathrm{Si}>$ de tal forma que algum aspecto de Fi ou algum aspecto de Si não é estritamente previsível a partir das partes componentes de $\mathrm{C}$ ou

7 Sucintamente, uma perífrase verbal pode ser entendida como a conjunção de um verbo e de uma forma nominal (infinitivo, gerúndio ou particípio), muitas vezes ligados por preposição, que tem como função marcar determinada categoria gramatical, como o tempo, ou uma noção semântica qualquer, como a modalidade (TRAVAGLIA, 1986; BARROSO, 1994). 
de outras construções previamente estabelecidas. (GOLDBERG, 1995, tradução nossa ${ }^{8}$ ).

Qualquer padrão linguístico é reconhecido como uma construção desde que algum aspecto de sua forma ou função não seja estritamente previsível a partir de suas partes componentes ou outras construções existentes. Ademais, padrões são armazenados como construções, mesmo que sejam totalmente predizíveis, desde que ocorram com suficiente frequência. (GOLDBERG, 2006, tradução nossa $\left.{ }^{9}\right)$.

Discorrendo sobre os princípios que regem as construções linguísticas e as atividades cognitivas humanas, de modo geral, Goldberg (1995, tradução nossa) cita o chamado Princípio da Não-Sinonímia: ${ }^{10}$

O Princípio da Não-Sinonímia: Se duas construções forem sintaticamente distintas, então elas precisam ser semântica ou pragmaticamente distintas (cf. Bolinger 1968; Haiman 1985; Clark 1987; MacWhinney 1989). Os aspectos pragmáticos incluem particularidades da estrutura informacional, tais como tópico e foco, e, adicionalmente, aspectos estilísticos da construção, tais como registro.

Colorário A: Se duas construções forem sintaticamente distintas e S(emanticamente) sinônimas, então elas precisam não ser $\mathrm{P}$ (ragmaticamente) sinônimas.

Corolário B: Se duas construções forem sintaticamente distintas e P-sinônimas, então elas precisam não ser S-sinônimas.

Na pesquisa aqui descrita, adotamos o termo construção aspectual, pois nos alinhamos à corrente da Gramática de Construções, ao

8 Do original: " $\mathrm{C}$ is a construction iff ${ }_{\text {def }} \mathrm{C}$ is a form-meaning pair $<\mathrm{Fi} \mathrm{Si}>$ such that some aspect of $\mathrm{F}$, or some aspect of $\mathrm{S}$, is not strictly predictable from C's component parts or from other previously established constructions". (GOLDBERG, 1995, p. 4).

9 Do original: "Any linguistic pattern is recognized as a construction as long as some aspects of its form or function is not strictly predictable from its component parts or from other constructions recognized to exist. In addition, patterns are stored as constructions even if they are fully predictable as long as they occur with sufficient frequency". (GOLDBERG, 2006, p. 5).

10 Do original: "The Principle of No Synonymy: If two constructions are syntactically distinct, they must be semantically or pragmatically distinct (cf. Bolinger 1968; Haiman 1985a; Clark 1987; MacWhinney 1989). Pragmatic aspects of constructions involve particulars of information structure, including topic and focus, and additionally stylistic aspects of the construction such as register [...].

Corollary A: If two constructions as syntactically distinct and S(emantically)-synonymous, then they must not be P(ragmatically)-synonymous.

Corollary B: If two constructions as syntactically distinct and P-synonymous, then they must not be S-synonymous". (GOLDBERG, 1995, p. 67). 
nos basearmos no princípio descrito acima e nas construções de estrutura argumental (GOLDBERG, 1995), ou diáteses (PERINI, 2008), para nortear as análises que nos propusemos a fazer.

\section{Resultados e discussões}

Com o levantamento dos dados nos corpora selecionados, conseguimos identificar cinco tipos de construções em que o verbo começar está presente e verificamos, em Perini (2008), outro tipo de construção que não ocorreu nos dados coletados - portanto, seis tipos. Para nos auxiliar a identificar tais construções, utilizamos a lista de diáteses apresentada por Perini (2008).

Nossos dados acusaram que, tanto na fala quanto na escrita dos três séculos analisados, a construção perifrástica $<\mathrm{V} 1_{\text {COMEÇAR }}+(\mathrm{a})+\mathrm{V} 2>$, tida como a perífrase aspectual inceptiva canônica, é a mais frequente e também a mais sujeita a variações do $\mathrm{V} 2$ :

( 2 ) “Comecei a pensar na Stela." (DRUMMOND, 1984).

( 3 ) "O trem tá começando a ficar bagunçado." (C-ORAL-BRASIL).

Entendemos que essa construção é mais passível de variação, porque nela o verbo começar atua somente como um auxiliar, mas o V2 pode ser preenchido por uma ampla gama de tipos verbais, o que faz dela uma construção bastante aberta, em virtude da ampla possibilidade de seleção do segundo verbo. ${ }^{11}$ Como ilustra o exemplo (4), tal construção apareceu, inclusive, como um constituinte menor de construções idiomáticas, conhecidas por sua natureza idiossincrática:

( 4 ) “O Galo toma de um a zero, Zé, o bicho já começa...” (C-ORAL-BRASIL).

No exemplo (4), mesmo com o V2 implícito (“a pegar”), o sentido básico da construção idiomática não se modifica. Para Reich (2011), esse é um forte argumento para atestar que começar é um autêntico verbo auxiliar. Esse forte traço de auxiliaridade do verbo começar, a nosso ver, justifica a alta frequência da construção $<\mathrm{V} 1_{\text {COMEÇAR }}+($ a) $+\mathrm{V} 2>$ nos dados coletados, pois, ao se gramaticalizarem, as formas tendem a se tornar mais frequentes. (HOPPER; TRAUGOTT, 2003). A frequência da construção citada aumentou com o passar dos séculos, em nossas amostras de escrita (séc. XIX =20,9\%; séc. XX =34,6\%; séc. $\mathrm{XXI}=44,5 \%$ ) e de oralidade (séc. $\mathrm{XIX}=6,7 \%$; séc. $\mathrm{XX}=42,2 \%$; séc. $\mathrm{XXI}=$

11 Para Reich (2011), essa ampla seleção do V2 para a construção perifrástica com começar se justifica pelo fato de que qualquer situação deve ter um começo, salvo algumas restrições com certos verbos estativos. 
$51,1 \%$ ), o que demonstra seu processo de expansão na língua.

Um segundo tipo de construção identificada, agora com o verbo começar sendo a única forma verbal da construção (verbo principal, portanto), foi a construção intransitiva de perspectiva ergativa, da qual tratamos brevemente na seção introdutória deste artigo:

( 5 ) “Vou deixá-la, o movimento começa daqui a pouco." (COELHO, 2003).

( 6 ) "Então não era qualquer um que tinha o rádio. E aí é que começou já $a$ minha paixão, mesmo porque eu não podia ver uma bola." (PEUL).

Observando a ergatividade desse tipo de construção, percebemos que o papel temático dos sujeitos é, de certa maneira, diferente do conceito normalmente atribuído ao papel temático de paciente ${ }^{12}$. O paciente é, em termos gerais, o papel temático afetado pela ação expressa pelo verbo, o que ocasiona, muitas vezes, mudança de estado do termo paciente. (CANÇADO, 2013). Nas construções com começar de padrão $<\mathrm{SN}_{\text {PACIENTE }} \mathrm{V}_{\text {COMEÇAR }}>$ ou $<\mathrm{V}_{\text {COMEÇAR }} \mathrm{SN}_{\text {PACIENTE }}>$, contudo, o sujeito não sofre a mudança de estado própria do paciente, pois ele não existia antes para sofrer tal mudança. ${ }^{13}$ Por outro lado, ele sinaliza uma mudança de estado do contexto temporal externo: momento anterior/evento ausente $>$ início do evento $>$ momento posterior/evento presente. Tal fato, contudo, não deixa de configurar uma mudança de estado (RAFAEL, 2016). Ciríaco (2007), por exemplo, inclui esse tipo de mudança, chamado de mudança de estado de existência, naquilo que classifica como uma noção bem ampla de estado, que é uma propriedade do papel temático do afetado. Portanto, a ergatividade da construção com começar aqui tratada é ratificada.

Outra característica dessa construção é a ocorrência, embora em menor frequência, de SNs concretos como argumentos do verbo começar:

( 7 ) "Ha algumas delas [ruas] que começam largas como 'boulevards' e acabam estreitas que nem vielas." (BARRETO, 1915, inserções nossas).

( 8 ) “A Rue de Berne começava em uma igreja.” (COELHO, 2003).

Estes exemplos, ambos pertencentes à língua escrita, foram os únicos do corpus

12 Estamos considerando que os papéis temáticos dos SNs destacados em (05) e em (06) são pacientes por se tratar de construção ergativa. Empiricamente, um movimento ou uma paixão são afetados por algo que desencadeia sua fase inicial. Cançado et. al. (2013), ao argumentar em favor da linguagem de decomposição de predicados, explica que "pode haver pelo menos três tipos de afetação: um 'paciente', afetado fisicamente, que muda de estado, um 'tema', que seria o participante afetado em seu deslocamento, e ainda um 'possuidor'ou 'beneficiário', um participante afetado em suas posses". (CANÇADO et. al.,2013, p. 112-113).

13 Essa alternância pode ser explicada formalmente pela hipótese inacusativa, em que o argumento interno afetado é alçado para a posição de sujeito, na estrutura superficial. (CIRÍACO, 2007). 
em que o SN paciente é expresso por nome concreto. A inceptividade, como tipo aspectual, não se manifesta nesses casos, pois não há a duração de um fato sendo descrita. Em (07), por exemplo, o verbo começar apenas atribui característica ao nome rua, o que é feito juntamente com os predicativos e com os adjuntos adverbiais presentes nas construções. Além da distinção entre concreto/abstrato, levantamos o questionamento sobre a classificação do papel temático desses SNs concretos: serão eles também afetados, pacientes? Acreditamos que não.

Por meio dessas constatações, podemos afirmar que as construções ergativas com começar marcam o início de uma situação, desde que o $\mathrm{SN}_{\text {SUJEITo }}$ seja abstrato. Elas, inclusive, são listadas por Travaglia (1986), no rol de construções aspectuais inceptivas. No entanto, até o momento, apesar da diferença sintática, não conseguimos flagrar uma diferença semântico-pragmática contundente (com exceção dos elementos concretos descritos no parágrafo anterior) entre essas e as construções perifrásticas inceptivas canônicas, em relação à marcação do aspecto inceptivo, à exceção de que o papel temático das construções concretas não parece ser o de paciente prototípico, o que poderia configurar outro padrão construcional.

Uma terceira construção com começar identificada nos corpora, a qual não encontramos em Perini (2008), segue o padrão $<\mathrm{SN}_{\text {SUJEITO }}+\mathrm{V}_{\text {COMEÇAR }}+$ SPrep $_{\text {POR }}>$ :

( 9 ) "Nos aniversários de nascimento, era um soneto que começava sempre por - salve! - e acabava também por - salve! Tres vezes salve!” (BARRETO, 1915).

(10) "É melhor [nós] irmos devagar, começar[mos] pelo mais fácil." (BARRETO, 1915, inserções nossas).

(11) "Demais, o fim tragico que queria dar a uma cousa que começou por idylio... devia assustá-lo.” (ASSIS, 1863).

Nessas construções, o SN sujeito aparece ora como agente (10), ora como paciente da ação ( 9 e 11), e o SPrep pós-verbal pode ser constituído tanto um por SN quanto por um verbo no infinitivo (cf. (12)). Não encontramos, nos dados analisados, complementos verbais do SPrep. No entanto, essa construção está presente na literatura que trata do aspecto inceptivo:

(12) “... e como se tivesse explicações a dar-me começou por dizer que se chamava Krauss...” (exemplo extraído de ALMEIDA, 1980, p. 44).

As construções em que o SPrep é complementado por um verbo podem se apresentar com o padrão $<\mathrm{SN}_{\text {SUJEITO }}+\mathrm{V}_{\text {COMEÇAR }}+$ GERÚNDIO $>$, sendo, de acordo com Barroso (1994), construções variantes:

(12a) [...] e como se tivesse explicações a dar-me começou dizendo que se 
chamava Krauss [...]

Encontramos uma única construção com o gerúndio nos dados coletados, a qual parece também poder ser construída com o SPrep iniciado por POR, o que comprova a tese da variação linguística apresentada por Barroso (op. cit.)

"Ele começou pintando árvore assim." (C-ORAL-BRASIL).

(13a) Ele começou por pintar árvore assim.

Ambas as construções acima, assim como as outras anteriormente apresentadas no terceiro tipo de construção com começar, são semelhantes na interpretação com o gerúndio e com o $\mathrm{SPrep}_{\mathrm{POR}}$, a qual indica que algo ou que alguém começou alguma coisa (uma atividade, uma profissão, um ato enunciativo, entre outros), fazendo aquilo que o gerúndio ou o SPrep sinalizam. Tal organização construcional traz, portanto, a ideia de ordenação, algo que pode ser visto, inclusive, com complementos concretos do SPrep (o verbo começar, nesses casos, não é auxiliar):

(14) "Se havia algum motivo para suspeitas naquela sexta-feira, [...], era o fato de que todos, a começar [começando] por Adam Cohen, acreditavam que podiam ser muito felizes." (DRUMMOND, 1984, inserções nossas).

Em outras palavras, a situação descrita no sintagma pós-verbal indica a primeira situação de uma série de outras pertencentes a um evento maior. Travaglia (1986) salienta que essas construções não marcam aspecto e Barroso (1994) insere-as no denominado aspecto de colocação/ordenação, e não no aspecto de fase inicial. De fato, as construções em questão não marcam a inceptividade, em termos aspectuais; apenas indicam o ordenamento de fatos, algo que pode explicar, por exemplo, a ocorrência de um locativo em construções negativas:

(15) "Não sei por onde começar, e nem sei se quero começar." (COELHO, 2003).

O quarto tipo de construção encontrado nos dados coletados é a construção transitiva. No entanto, um aspecto formal subdivide essa construção em duas: o tipo de realização do objeto direto. Identificamos construções transitivas com o objeto direto expresso, e outras com tal complemento elíptico, estas com frequência muito superior (83,3\%) àquelas (16,7\%). Os exemplos (16) e (17) ilustram as construções transitivas com o objeto expresso, e os dois subsequentes, a construção transitiva com o objeto elíptico:

(16) "Tinham começado a partida, quando dona Quinota, uma das filhas do general, atravessou a sala e foi beber água.” (BARRETO, 1915).

(17) Finalmente parou por um instante, talvez para respirar, e começar novo 
ataque de maçada." (MACEDO, 1844).

(18) "Foi assim que você começou... isto cheira a segunda edição, hein?" (PEDERNEIRAS, 1931).

(19) “Pia, quando começa, minha filha..." (C-ORAL-BRASIL).

Algo interessante a ser observado é o papel temático de paciente do sujeito de (19). De acordo com Perini (2008), a construção transitiva tem os padrões $<\mathrm{SN}_{\text {SUjeIto }}+\mathrm{V}+\mathrm{SN}_{\text {OвJETO }}>\mathrm{e}<\mathrm{SN}_{\text {SUjerto }}+\mathrm{V}+\varnothing>$, em que o sujeito é agente e o objeto, paciente. No entanto, em (19), a pia não é o agente do evento em elipse (a estragar, a dar defeito...); mesmo assim, a construção, aparentemente ${ }^{14}$, permanece a mesma da transitiva de objeto elíptico.

Além de o papel de paciente poder ser atribuído ao sujeito, percebemos que o objeto elíptico pode ser preenchido por sintagmas diferentes (20), o que causa, em alguns casos, uma ambiguidade construcional (21):

(20) "E comece logo [o turno de trabalho? a trabalhar? a procurar homem?...]. Se voltar hoje para casa sem ter arranjado um homem, irá pensar duas vezes, e não terá coragem de voltar." (COELHO, 2003, inserções nossas).

(21) "Só encenação e procissão [...] noh, es andava demais, começava lá na praça [a procissão começava na praça ou "es" começavam a andar demais a partir da praça?], com o telão, com a encenação de ano passado...” (C-ORALBRASIL, inserções nossas).

Mesmo as construções com o objeto expresso podem comportar construções perifrásticas em sua estrutura argumental (exemplos 22, 23 e 24), as quais, em alguns casos, também podem ser ambíguas, como em (22), se a sequência textual posterior não se encarregar de indicar a atividade pretendida pelo falante:

(22) "Sentou-se e quiz começar [a cantar? a recitar?] uma modinha sobre a Gloria. [...] Tentou começar [a compor], dispoz o papel, mas não pôde." (BARRETO, 1915, inserções nossas).

(23) "O estudante depois de certificar-se que toda a companhia estava longe, veio sentar-se junto da Senhora dona Anna no banco de relva, e começou [a contar] a história de seus amores." (MACEDO, 1844, inserções nossas).

(24) João quis começar um namoro com Maria / a namorar Maria, mas ela não quis. (dado de introspecção)

$\mathrm{Na}$ análise de alguns dados de introspecção $(25,25 \mathrm{a}$ e $25 \mathrm{~b})$, ao testarmos a

14 Dizemos aparentemente porque, dado o papel temático, essa pode ser também uma variante da construção ergativa já descrita, o que ainda demanda mais investigação. 
alternância citada, percebemos que as perífrases só podem figurar nos contextos de objeto direto com o traço [+abstrato]; construções transitivas com objetos concretos não permitem tal permutação. Pelo que pudemos observar, a alternância entre o SN e o verbo é permitida a partir de um nome abstrato denotativo de ação, conforme (25a e 25b):

(25) O pedreiro começou o canil ontem.

(25a) O pedreiro começou a construção do canil ontem.

(25b) O pedreiro começou a construir o canil ontem.

De todas as construções identificadas, apenas a transitiva permite a alternância entre objeto direto (especialmente o elíptico) e a perífrase inceptiva. Além disso, tal como a construção perifrástica $<\mathrm{V} 1_{\text {COMEÇAR }}+(a)+V 2>$, a construção transitiva de objeto implícito foi bastante recorrente nos dados dos três séculos. Por esses motivos, categorizamos essas construções transitivas mais próximas da perífrase inceptiva canônica. A inceptividade aspectual parece não se aplicar, no entanto, à construção transitiva de objeto explícito, devido à aproximação dessa construção com a que explicitaremos agora.

A última construção que identificamos com o verbo começar foi tratada por Perini (2008) como uma diátese praticamente exclusiva dos verbos incoativos: $<\mathrm{SN}_{\text {AGENTE }}+\mathrm{V}+\mathrm{SPrep}_{\text {PACIENTE }}>$ sem objeto direto. O termo incoativo é utilizado para indicar que há mudança de estado, neste caso, do SPrep paciente. $\mathrm{O}$ autor, no entanto, não fornece um exemplo com o verbo começar propriamente dito, apenas como o verbo acabar ("Toninho acabou com a festa."), o que nos levou a elaborar os exemplos (27) a (29) e a inserir o (26), retirado dos dados analisados:

(26) "Esses caras aqui que começaram com esse lance de arquitetura artística." (C-ORAL-BRASIL).

(27) João começou com a algazarra.

(28) João começou a algazarra.

(29) A algazarra começou.

Julgamos, pelos exemplos (26) e (27), que a preposição com é somente uma marca morfológica de mudança de diátese, o que nos leva a analisar o sintagma pós-verbal, nos termos da Gramática Tradicional, como um objeto direto preposicionado de preposição facultativa. ${ }^{15}$ Indo, portanto, na direção contrária à de Perini (2008), cremos que há, sim, a presença do objeto direto junto do verbo

15 Adaptamos a expressão "marca morfológica de mudança de diátese" de Ciríaco (2007). A autora utiliza-a para falar de outra marca, no caso, do vocábulo se. 
começar, o que encaixa a referida construção, então transitiva, nas chamadas construções causativas (ARRAIS, 1985), em que há um evento-causa (Esses caras / João) e um evento-efeito (esse lance de arquitetura/ a algazarra).

De acordo com Ciríaco (2007), os verbos basicamente intransitivos (ou inacusativos - ex. 30) aceitam o processo de causativização, podendo ser a causa inferível ou não. Verificamos, portanto, que a construção aqui tratada está relacionada à construção ergativa, a qual, por meio da causativização (CIRÍACO, 2007), passou a ser transitiva. Por esse motivo, dizemos que as construções transitivas de objeto explícito que encontramos, de fato, nos corpora, parecem se encaixar na perspectiva da causativização, pois a ergativa/inacusativa é possível, devido à presença do objeto direto paciente/afetado, e a forma apassivada permite a inferência do desencadeador do início do evento, conforme pode ser visto no exemplo retomado a seguir:

(30) "Tinham começado a partida." (BARRETO, 1915).

(30a) A partida começou / foi começada [pelos homens/jogadores].

Estamos conscientes de que mais exemplos devam ser analisados para a validação de nossa proposta, uma vez que foram baixas as ocorrências da construção transitiva de objeto explícito em nossos corpora. Mesmo assim, defendemos que não há inceptividade se manifestando nessa construção, pois o evento-causa (ou o desencadeador) não representa a temporalidade interna (condição para o aspecto) do evento-efeito. "João" (ex. 27 e 28) e o sujeito elíptico (ex. 30) são apenas os desencadeadores, as causas do início da algazarra e da partida; o início dos eventos, propriamente, pode ter sido concomitante (ex. 27/28 e 30) ou posterior à causa (interpretação aplicável ao ex. 30).

Duas ocorrências de construções com começar, encontradas nos dados da oralidade do século XX, não se encaixaram, aparentemente, nos tipos apresentados anteriormente. São estas:

(31) "Na primeira semana, eu comecei com quinhentos cruzeiros ou quinhentos mil réis, não me lembro agora." (PEUL).

(32) "Começamos como empregado, quer dizer, como empregado." (PEUL).

As duas estruturas trazem SPreps, mas não se encaixam na mesma categorização. Em (32), poderíamos dizer que há uma nomeação dos sujeitos, o que faz com que essa construção se encaixe nos padrões da diátese de nomeação com SPrep, tratada por Perini (2008); no entanto, na classificação de Perini (2008), há um objeto paciente ao qual é atribuído a nomeação $\left(\mathrm{SN}_{\text {SUJEITO }}+\mathrm{V}+\mathrm{SN}_{\text {PACIENTE }}+\right.$ 
SPrep $_{\mathrm{COMO+SN}}$ ), o que não ocorre na sentença apresentada em (32). Já, para (31), não conseguimos encontrar, até o momento, uma diátese específica que representasse a construção citada. Salientamos, contudo, que, a nosso ver, há SNs ou verbos implícitos em ambas as construções, apesar de não sabermos precisar quais são. Mesmo assim, mais testes são necessários para se verificar tanto a produtividade dessas construções quanto as diáteses possíveis com cada uma, para que sejam apresentadas conclusões mais contundentes. De qualquer maneira, o aspecto inceptivo não se manifesta nas construções citadas, se consideradas as estruturas tal como elas se apresentam.

Para finalizarmos essa breve análise, retomamos o Princípio da Não-Sinonímia, descrito por Goldberg (1995). Percebemos que algumas das construções aqui tratadas são sintática, semântica e pragmaticamente diferentes entre si, no que diz respeito à fase inicial do processo verbal, como, por exemplo, as construções perifrásticas e as construções com o $\operatorname{SPrep}_{\mathrm{POR}}$ (colocação). Outras, no entanto, não deixam claras entre si certas diferenças semântico-pragmáticas. Por exemplo, a construção de colocação permite a alternância gerúndio/Sprep ${ }_{\mathrm{POR}}$ sem acarretar prejuízo ou diferença semântico-pragmática à estrutura As construções causativas também parecem não se modificar em relação à presença ou à ausência da preposição com. Por último, não pudemos precisar o grau de relação entre as construções de objeto elíptico e as construções perifrásticas, nem até que ponto as diferenças entre as construções ergativas e perifrásticas (as quais, na nossa concepção, expressam o aspecto inceptivo) são suficientes para dizer se elas são construções totalmente diferentes ou se elas mantêm, entre si, relações de herança.

\section{Considerações finais}

Pretendemos, com este estudo, identificar e descrever as construções em que o verbo começar aparece no PB, para analisarmos a noção de inceptividade aspectual possivelmente veiculada em cada uma. Com base no Princípio da NãoSinonímia de Goldberg (1995), lançamos a hipótese de que o aspecto inceptivo não seria atualizado de maneira equivalente em todas as construções, ou, até mesmo, que ele não seria marcado por algumas delas, mesmo que todas tenham a noção de princípio latente na significação do verbo começar, hipótese confirmada por nossos dados.

Com a análise de alguns dados coletados, nas modalidades oral e escrita do PB, 
dos séculos XIX ao XXI, conseguimos identificar, dentre algumas observações, seis tipos de construção diferentes em que o verbo começar figura: (i) intransitivas de perspectiva ergativa, (ii) transitivas de SN objeto explícito, (iii) transitivas de SN ou verbo elíptico, (iv) perifrásticas canônicas (mais frequentes), (v) de ordenação e (vi) causativas (menos frequentes e, aparentemente, variantes das transitivas de objeto explícito). Duas ocorrências não se encaixaram num modelo específico de diátese, por isso não as contabilizamos nos tipos de construção encontradas; estudos mais aprofundados sobre suas estruturas precisam ainda ser feitos.

Com relação à inceptividade ligada à categoria linguística aspectual, verificamos que a perífrase $<\mathrm{V} 1_{\text {COMEÇAR }}+(a)+V 2>$ é sua representante por excelência, tal como descrito na literatura sobre o tema. Consideramos que as construções ergativas também expressam o aspecto, algo que outros pesquisadores, como Travaglia (1986), também abordam em seus trabalhos. Entretanto, tal como afirmamos anteriormente, não sabemos ainda dizer, ao certo, o que motiva essas duas construções, mesmo que elas marquem a fase inicial de uma situação. Outras construções que levantaram questionamentos, mesmo não expressando aspecto, foram as construções de ordenação (por permitirem a alternância de sintagmas sem acarretar alternância de sentido) e as causativas (pela alternância do uso da preposição com), o que parece colocar em xeque alguns pressupostos do Princípio da Não-Sinonímia.

\title{
Constructions with the verb começar in Brazilian Portuguese and the aspectual notion of inceptivity
}

\begin{abstract}
In this study, we intented to identify the different types of constructions in which the verb começar appears in Brazilian Portuguese in order to verify how the inceptive aspect occurs in each one of these constructions, once this verb is the most frequent verb in the aspectual category under analysis. (TRAVAGLIA, 1986; BARROSO, 1994). Our research was based on the Construction Grammar postulates, more specifically on Goldberg's Principle of Non-Synonymy (1995), to hypothesize that the inceptive aspect does not occur in all constructions with começar in the same way. The analyzed data were extracted from oral and written texts of Brazilian Portuguese, from $19^{\text {th }}$ to $21^{\text {st }}$ century. The results showed, at first sight, six types of constructions, as the periphrastic and the ergative ones. Concerning the inceptive aspect occurrence, we have faced some limitations in our analysis, but we verified some possible problems which
\end{abstract}


go against Goldberg's Principle of Non-Synonymy (1995).

Keywords: Inceptive aspect. Verb COMEÇAR. Construction Grammar.

Principle of Non-Synonymy. Brazilian Portuguese.

\section{Referências}

ALMEIDA, João de. Introdução ao estudo das perífrases verbais de infinitivo. Assis, São Paulo: ILHPA - HUCITEC, 1980.

ARRAIS, Telmo Correia. As construções causativas em português. Alfa, São Paulo, n. 29, p. 41-58, 1985.

BARROSO, Henrique. $O$ aspecto verbal perifrástico em português contemporâneo: visão funcional / sincrónica. Porto: Porto Editora, 1994.

BRAGA, Maria Luiza; PAIVA, Maria da Conceição de. Gramaticalização e Gramática de Construções: estabilidade e instabilidade no uso de orações complexas de causa em tempo real. Rev. Let. \& Let. Uberlândia-MG, v.27, n.1, p.51-70, jan./jun. 2011.

CANÇADO, Márcia. Manual de semântica: noções básicas e exercícios. $1^{\mathrm{a}} \mathrm{ed}$. São Paulo: Contexto, 2013.

CANÇADO, Márcia; GODOY, Luisa; AMARAL, Luana. Predicados primitivos, papéis temáticos e aspecto lexical. ReVEL, v. 11, n. 20, 2013.

CIRÍACO, Larissa Santos. A alternância causativo-ergativa no PB: restrições e propriedades semânticas. 2007. Dissertação (Mestrado em Linguística) Faculdade de Letras, Universidade Federal de Minas Gerais, Belo Horizonte. 2007.

COMRIE, Bernard. Aspect: an introduction to the study of verbal aspect and related problems. New York: Cambridge University Press, 1976. COSTA, Sônia Bastos Borba. O aspecto em português. São Paulo: Contexto, 1990.

CROFT, W. A. Construction grammar. In.: GEEREARTS, D.; CUYCKENS, H. The Oxford Handbook of Cognitive Linguistics. Oxford: Oxford University Press, 2007.

FERRARI, Lilian. Modelos de gramática em Linguística Cognitiva: princípios convergentes e perspectivas complementares. Caderno de Letras da UFF Dossiê: Letras e Cognição, nº 41, p. 149-165, 2010. 
FILLMORE, C. J.; KAY, P.; O'CONNOR, M. C. Regularity and idiomaticity in grammatical constructions: The case of let alone. Language. vol. 64, n. 03, p. 501-538, sep. 1988.

GOLDBERG, A. E. Constructions: a construction grammar approach to argument structure. Chicago: The University of Chicago Press, 1995.

HOPPER, Paul; TRAUGOTT, Elizabeth. Grammaticalization. $2^{\mathrm{a}}$. ed. Cambridge: Cambridge University Press, 2003.

PERINI, Mário Alberto. Estudos de gramática descritiva: as valências verbais. São Paulo: Parábola, 2008.

REICH, Núbia Ferreira. O processo de auxiliaridade verbal no português brasileiro: uma análise dos aspectuais. Revista Letras, Curitiba, n. 84, p. 111-136, jul./dez. 2011.

SIGILIANO, Natalia Sathler. A construção aspectual inceptiva do português com verbos não canônicos. 2013. Tese (Doutorado em Linguística) - Faculdade de Letras, Universidade Federal do Rio de Janeiro, Rio de Janeiro. 2013.

SIGILIANO, Natalia Sathler. Evidências translinguísticas da metáfora de movimento na Construção de Aspecto Inceptivo. Revista LinguíStica / Revista do Programa de Pós-Graduação em Linguística da Universidade Federal do Rio de Janeiro, v. 8, nº. 1, junho de 2012.

TRAVAGLIA, Luiz Carlos. O aspecto verbal no português: a categoria e sua expressão. Ed. rev. Uberlândia: Universidade Federal de Uberlândia, 1985.

\section{Corpora da pesquisa:}

ALENCAR, José de. Verso e reverso: comédia em 2 actos. $2^{\mathrm{a}}$ ed. rev. pelo autor. Rio de Janeiro: Garnier, 1864.

ARANHA, Graça. Malazarte. Rio de Janeiro: F. Briguiet e cia., 1911.

ASSIS, Machado de. O caminho da porta: comédia em um acto. In: Theatro de Machado de Assis. Vol. 1. Rio de Janeiro: Typ. do Diário do Rio de Janeiro, 1863. p. 1-42.

AZEVEDO, Aluísio. Casa de Pensão: tipos e fatos. $3^{\text {a }}$ ed. (popular). Rio de Janeiro: Faro e Lino, 1884.

BARRETO, Lima. Triste fim de Policarpo Quaresma. Rio de Janeiro: Typ. Revista dos Tribunaes, 1915. 
COELHO, Paulo. Onze minutos. Rio de Janeiro: Rocco, 2003.

DRUMMOND, Roberto. Hitler manda lembranças. Rio de Janeiro: Nova Fronteira, 1984.

MACEDO, Joaquim Manoel de. A Moreninha. Rio de Janeiro: Typ. Francesa, 1844.

PEDERNEIRAS, Raul. O chá do Sabugueiro: comédia em 3 actos, sobre costumes cariocas. Rio de Janeiro: Sociedade Brasileira de Autores Teatrais, 1931. PENA, Martins. Juiz de paz na roça: comédia em um acto. Rio de Janeiro: Cruz Coutinho, 1871.

PENA, Martins. O noviço: comédia em três actos. Rio de Janeiro: Casa Imperial, 1853.

PEUL: Programa de Estudos sobre o Uso da Língua. Universidade Federal do Rio de Janeiro.

RASO, Tommaso; MELlO, Heliana (orgs.). C-ORAL-BRASIL: Corpus de Referência do Português Brasileiro Falado Informal. Belo Horizonte: Editora UFMG, 2012.

Submetido:27/03/2016

Aceite: 06/09/2016 